\title{
Oral Semaglutide In The Management Of Type 2 Diabetes: A Report On The Evidence To Date
}

This article was published in the following Dove Press journal:

Diabetes, Metabolic Syndrome and Obesity: Targets and Therapy

\author{
Sam Pearson (iD) ${ }^{1, *}$ \\ Noppadol Kietsiriroje (D) ${ }^{1,2, *}$ \\ Ramzi A Ajjan' \\ 'Leeds Institute of Cardiovascular and \\ Metabolic Medicine, Faculty of Medicine \\ and Health, University of Leeds, Leeds, \\ West Yorkshire LS2 9jT, UK; ${ }^{2}$ Division of \\ Endocrinology and Metabolism, \\ Department of Internal Medicine, Faculty \\ of Medicine, Prince of Songkla University, \\ Hatyai, Songkhla 90I 10, Thailand \\ *These authors contributed equally to \\ this work
}

\begin{abstract}
In recent years, newer drug classes for the treatment of type 2 diabetes mellitus have been released with significant effects on glucose lowering and weight reduction. One of the most promising classes in achieving these goals has been the glucagon-like peptide (GLP)-1 agonists. However, a difficulty with the use of these agents is the need for subcutaneous injections, which can be inconvenient to individuals living with type 2 diabetes. More recently, a GLP-1 agonist has been developed, semaglutide, that can be administered orally which has at least similar effects to the subcutaneous preparation from which this compound is derived. In this review article, we discuss the glycemic and cardiovascular effects of the GLP-1 agonists with special emphasis on oral semaglutide and the potential role of this therapy in individuals with type 2 diabetes.
\end{abstract}

Keywords: oral semaglutide, type 2 diabetes, treatment, glucagon-like peptide 1

\section{Introduction}

The prevalence of type 2 diabetes (T2D) is on the increase worldwide, tightly linked to enlarging waistlines and the expanding number of individuals who are overweight and obese. The landmark UK prospective diabetes study (UKPDS) provided the first high-quality evidence that improving glycemic control in those with newly established T2D conclusively reduces rates of microvascular complications and long-term macrovascular disease. ${ }^{1,2}$ While outcome in intensively treated individuals was superior to those undergoing standard therapy, of concern was the weight gain and increased risk of hypoglycemia. It is worth reminding the readers that at the time of UKPDS, hypoglycemic therapies were largely limited to metformin, sulfonylureas, and insulin. New agents were developed since with the aim of reducing elevated glucose levels while limiting the risk of hypoglycemia. An unexpected change in direction occurred after the publication by Nissen and Wolski implicating rosiglitazone in adverse clinical outcome following meta-analysis. ${ }^{3}$ This precipitated a series of events culminating in the Food and Drug administration (FDA) requirement for cardiovascular safety studies for all new hypoglycemic agents. This has led to a wealth of information on newer agents, which unfortunately did not extend to older hypoglycemic drugs.

To date, a number of newer classes of medications used to treat T2D have been developed and subsequently released to market that effectively lower glucose levels while minimizing the risk of hypoglycemia and inducing weight loss. The two most promising of these classes to date are the sodium-glucose transport protein 2 inhibitors (SGLT-2i) and glucagon-like peptide-1 (GLP-1) agonists. Although
Leeds Institute of Cardiovascular and Metabolic Medicine, Faculty of Medicine and Health, University of Leeds, Leeds,

West Yorkshire LS2 9JT, UK

Tel +44 II33437475

Email r.ajjan@leeds.ac.uk 


\section{Box I What Are Summarized In This Review}

- Oral semaglutide is the first GLP-I receptor agonists administrated orally with similar glycemic efficacy compared with injectable liraglutide and semaglutide

- In head-to-head studies, oral semaglutide appears to be superior to empagliflozin and sitagliptin in relation to $\mathrm{HbAlc}$ and weight reduction

- Oral semaglutide does not increase risk of vascular events and may reduce all-cause mortality

- Oral semaglutide is generally well tolerated with a favorable safety profile

there are some inter-class differences, robust randomized controlled trials have demonstrated that use of some of these drugs can improve clinical outcome in individuals with T2D., ${ }^{4,5}$ A drawback of GLP-1 receptor agonists (GLP-1RAs) has been the need for injections, but a newer agent in this class, semaglutide has shown to be efficacious when administered orally. In this review article, we will discuss the glycemic and cardiovascular effects of the GLP-1 analogue class with special emphasis on oral semaglutide and the potential role of this therapy in individuals with type 2 diabetes. The key points for oral semaglutide were summarized in the Box 1.

\section{Physiology Of GLP-I}

GLP-1 is a 30 amino acid peptide hormone (GLP-1 7-36) (Figure 1) primarily secreted from the " $\mathrm{L}$ " and " $\mathrm{K}$ " cells of the intestinal tract. ${ }^{6}$ Its existence has been known for decades and its amino acid structure was discovered during investigations into its precursor, proglucagon, in the mid-1980s. ${ }^{7}$ Levels of this hormone rise dramatically following consumption of glucose, and to a lesser extent other nutrients, particularly when food reaches the duodenum. ${ }^{8}$ Secreted GLP-1 binds to its receptor (GLP$\mathrm{R})$ on pancreatic beta cells and other organs, including the kidney and brain. A member of the G-protein-coupled receptor superfamily, ${ }^{9}$ the binding of GLP-1 to GLP-R on pancreatic $\beta$-cells leads to an increase in insulin secretion, mainly due to an increase in cAMP production. ${ }^{9}$

One of the major factors affecting circulating levels of GLP-1 is the enzyme dipeptidyl peptidase-4 (DPP-4). DPP-4 is known to cleave a broad range of substrates, rendering them inactive including growth factors, neuropeptides, and vasoactive peptides. ${ }^{10}$ It also inactivates GLP-1 (and the other human incretin GIP) rapidly and thus activity of GLP-1 in non-augmented physiology is relatively short lived $\left(<2\right.$ mins in plasma).${ }^{11}$ For this reason, parenteral administration of GLP-1 in its native form results in quick clearance necessitating changes to amino acid structure for therapeutic use and prolonged half-life.

Outside the effects on the pancreas, GLP-1 modulates the gastro-intestinal tract, where it acts as a potent inhibitor of gastric emptying and causes a reduction in calorie transit from the stomach to the small intestine to a rate of approximately $1-4 \mathrm{kcal} / \mathrm{min}^{12,13}$ This leads to an increased feeling of satiety, helping to lose weight. In the brain, GLP-1 is produced locally in a discrete area of the lower brainstem ${ }^{14}$ and GLP-R is seen throughout much of the central nervous system, barring the cerebellum and cerebral cortex. ${ }^{15}$ Although most studies have been conducted on animals, GLP-1 amino acid structure is maintained throughout all mammalian species and thus generalizations of its effects on the human brain are likely to be similar. Intra-cerebral injections of GLP-1 in rats suppresses appetite, causes taste aversion and brings about changes in behavior and memory. ${ }^{16-18}$ Importantly, injection of GLP-R antagonists into rat brains significantly increases feeding and bodyweight even in well-fed animals, ${ }^{19}$ thus highlighting the point that GLP-R in the central nervous system is physiologically active.

In the cardiovascular system, GLP-1 has also been found to be physiologically active. The use of liraglutide has been shown to improve neointima proliferation following wire induced coronary artery damaged in diabetic mice. ${ }^{20}$ The same agent has also been shown to reduce endoplasmic reticular stress and improve endothelial function $^{21}$ in individuals with T2D and GLP-1 is thought to play a role in the vascular endothelial growth factor A (VEGFA) signaling pathway. ${ }^{22}$

\section{An Overview Of Existing Subcutaneous GLP-I Receptor Agonists}

Exenatide was the first GLP-1RA to market, receiving approval by the FDA in 2005. A number of other GLP-1 RA followed either as daily (liraglutide, lixisenatide) or weekly (extended-release exenatide, albiglutide, dulaglutide, and semaglutide). Albiglutide was marketed from 2014 but discontinued in 2018 for commercial reasons and will not be discussed here.

The hypoglycemic effect of these agents is beyond doubt with average $\mathrm{HbAlc}$ reduction ranging from $0.3 \%$ to $1.2 \%$ compared with placebo. This glycemic efficacy is preserved regardless whether it is used as monotherapy or 
<smiles>[X]C(=O)CCC(NCC)C(=O)O</smiles>

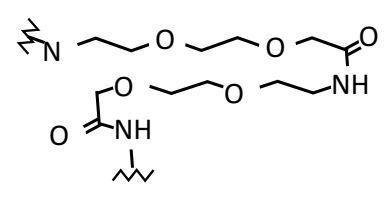

2x OEG<smiles>CC(C)(N)C(O)O</smiles>

Aib
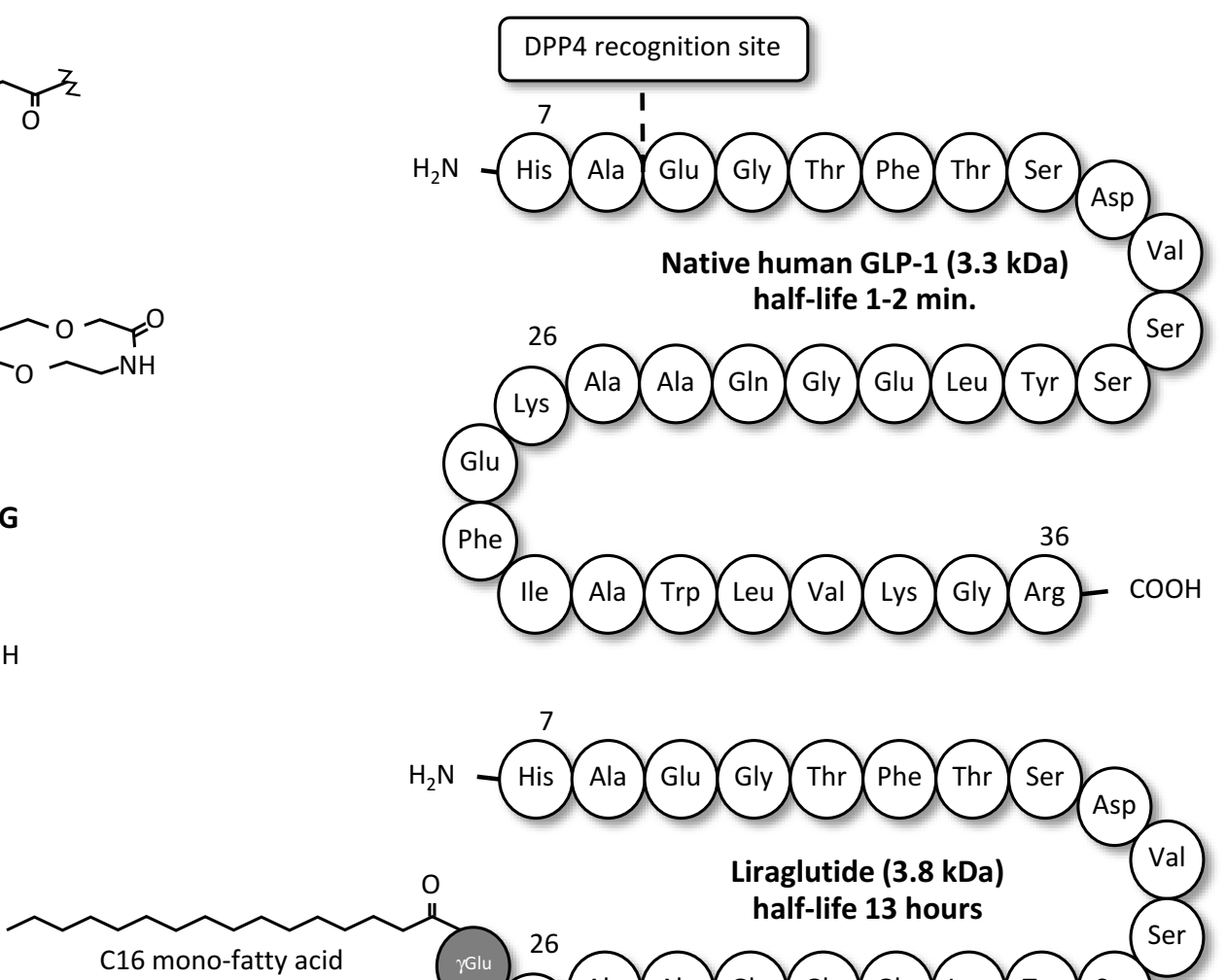<smiles>O=C(O)CCCCCCNC(=O)c1ccccc1O</smiles><smiles>CCCCCCCC1CCCCC1</smiles>

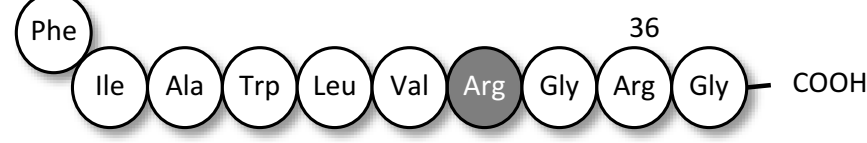

Salcaprozate sodium (SNAC)

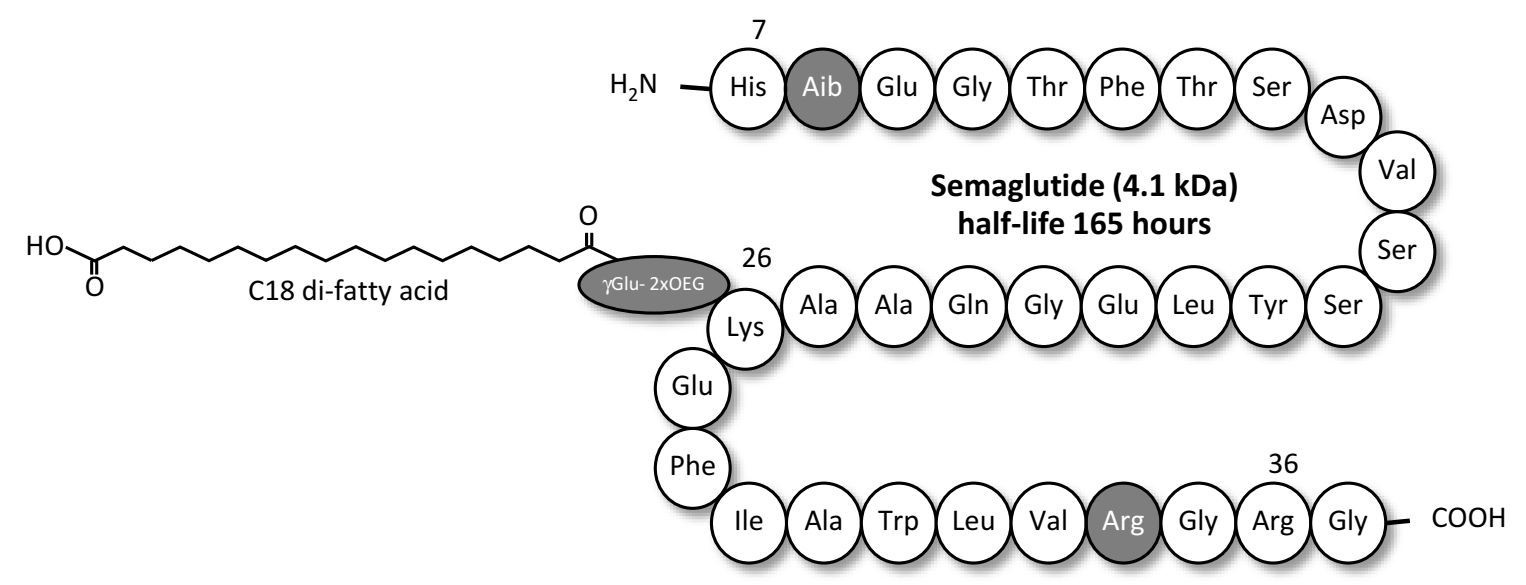

Figure I Structure and half-lives of native human GLP-I, liraglutide and semaglutide. Native human GLP-I is a 30 amino acid peptide hormone (GLP-I 7-36) with a short half-life of I-2 mins. Liraglutide is a once-daily, subcutaneously injectable GLP-I analogue, derivatized with CI6 mono-fatty acid by $\gamma$ Glu linker at Lys ${ }^{26}$ and substituted Lys ${ }^{34}$ by $\mathrm{Arg},{ }^{34}$ resulting in the plasma half-life of $13 \mathrm{hrs}$. Semaglutide is a once-weekly, subcutaneously injectable GLP-I analogue, derivatized with CI 8 di-fatty acid by $\gamma \mathrm{Glu}-2 \mathrm{x}$ "OEG" linker at $\mathrm{Lys}^{26}$ and substituted $\mathrm{Ala}^{8}$ by $\mathrm{Aib}^{8}$, and $\mathrm{Lys}^{34}$ by Arg, ${ }^{34}$ resulting in the plasma half-life of 165 hrs. Salcaprozate sodium (SNAC) (sodium 8-(2-hydroxybenzamido) octanoate) is an intestinal permeation enhancer. Data modified from Refs. 28, 54, and 55.

added to a single or a combination of hypoglycemic agents. ${ }^{23}$ The improvement in HbAlc is associated with significant weight loss making these agents attractive for the treatment of individuals with T2D. 
Given the FDA requirements of cardiovascular safety data with new hypoglycemic therapies, all GLP-1RA agents have undergone vascular outcome studies, which provided important data that will be briefly summarized here for each of the injectable agents in the class.

\section{Exenatide}

The cardiovascular effects of modified release exenatide were assessed in a randomized controlled trial (RCT) involving 14,752 individuals with T2D, of whom $>70 \%$ had existing cardiovascular disease (CVD) (EXSCEL). ${ }^{24}$ Over a median follow-up period of 3.2 years, exenatide proved to be non-inferior to placebo $(p<0.01)$ for the primary composite endpoint of death from cardiovascular causes, nonfatal myocardial infarction, or nonfatal stroke. Superiority was, however, narrowly missed with HR of 0.91 (CI: 0.83 to $1.00 ; p=0.06$ for superiority).

\section{Liraglutide}

The LEADER trial randomized high-risk individuals with T2D to liraglutide or placebo ${ }^{5}$ and enrolled 9340 patients. All study participants had a baseline HbA1c of $>7 \%$ and $81 \%$ had established CVD. Individuals were eligible if they were naïve to any hypoglycemic therapy, were taking oral agents, or were on combined therapy with oral agents and insulin. At 36 months, HbA1c was reduced by $0.4 \%$ (CI: -0.45 to -0.34 ) when comparing the Liraglutide group to placebo. There was a $13 \%$ reduction in the composite primary endpoint of cardiovascular death, nonfatal stroke, or non-fatal myocardial infarction (MI) [HR 0.87 (95\% CI, 0.78 to 0.97 ); $\mathrm{p}<0.001$ for noninferiority; $\mathrm{p}=0.01$ for superiority].

\section{Lixisenatide}

The ELIXA trial was designed to assess the cardiovascular safety of lixisenatide in high-risk T2D patients who had suffered acute coronary syndrome in the past 180 days. $^{25}$ This multicenter RCT recruited 6068 individuals and over a follow-up of 25 months, showed non-inferiority of lixisenatide compared with placebo in relation to the composite primary endpoint of death from cardiovascular causes, nonfatal MI, nonfatal stroke, and hospitalization for unstable angina [HR 1.02 (0.89 to 1.17)]. Of note, the difference in HbAlc between study arms was $-0.27 \%(95 \%$ CI -0.31 to $-0.22 ; \mathrm{p}<0.001)$ across all visits.

\section{Dulaglutide}

The recently published REWIND trial assessed the effects on cardiovascular outcome of dulaglutide in patients more than 50 years old who had T2D and had suffered either a previous cardiovascular event or had established risk factors. ${ }^{26}$ Participants were randomized to receive either $1.5 \mathrm{mg}$ weekly dulaglutide or placebo. A major difference between this trial and other GLP-1RA studies is the low percentage of individuals with established cardiovascular disease (CVD) at 31\%. With 9901 participants and a lengthy follow-up period of 5.4 years, there was a $12 \%$ reduction in the primary outcome (a composite of cardiovascular death, non-fatal stroke, and non-fatal MI) [HR 0.88, 95\% CI 0.79-0.99; $\mathrm{p}=0 \cdot 026$ ]. Interestingly, all-cause and cardiovascular mortalities did not differ between groups. Mean HbAlc was $7.2 \%$ in both groups at enrollment with a fall of $0.6 \%$ (CI 0.58 to $0 \cdot 65$ ) seen in those taking dulaglutide compared to placebo.

\section{Semaglutide}

The cardiovascular safety of subcutaneous semaglutide was assessed in the SUSTAIN-6 trial. ${ }^{27}$ This trial recruited 3297 participants all of whom had T2D and a baseline HBA1C $>7 \%$, who were randomized to two doses of semaglutide or volume matched controls. As high as $58.8 \%$ of the participants had established CVD without chronic kidney disease (CKD) with an additional $13.4 \%$ having both CVD and CKD. Over a median observation time of 2.1 years, a primary composite endpoint of death from cardiovascular cause, non-fatal MI, or non-fatal stroke occurred less frequently in semaglutide-treated individuals (HR 0.74, CI 0.58 to $0.95, \mathrm{p}<0.001$ for non-inferiority and $\mathrm{p}=0.02$ for superiority.) Regarding glycemic control, at 104 weeks, mean $\mathrm{HbAlc}$ was reduced by $0.7 \%$ in the $0.5 \mathrm{mg}$ dose versus placebo and $1.0 \%$ in the $1.0 \mathrm{mg}$ dose, both of which were statistically significant $(\mathrm{p}<0.001$.)

Key points regarding baseline characteristics and study outcomes for the major cardiovascular outcome trials in human GLP-1RA are summarized in Table 1.

\section{The Discovery Of Oral Semaglutide}

The short half-life of human GLP-1 resulting from degradation by DPP-4 has raised a challenge for pharmaceutical use in the clinical setting where a constantly high and stable plasma level is required. ${ }^{56}$ Reversible binding to albumin by using fatty acid derivatization is one approach 


\begin{tabular}{|c|c|c|c|c|c|c|c|c|c|c|c|c|c|c|}
\hline 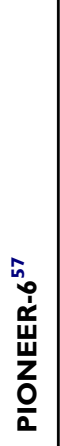 & 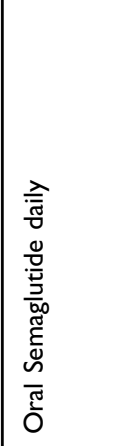 & $\frac{\varrho}{m}$ & $\underline{m}$ & 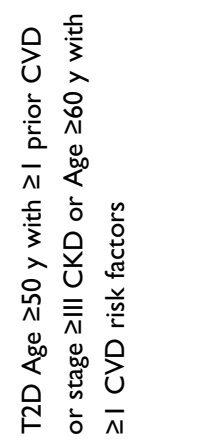 & 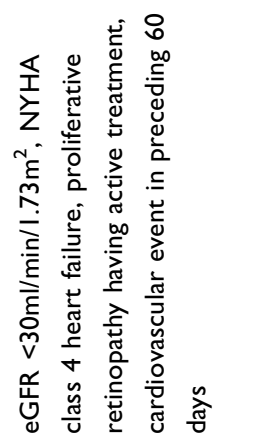 & $\begin{array}{l}\stackrel{\circ}{+} \\
\stackrel{\infty}{\infty}\end{array}$ & $\frac{0}{m}$ & ஃ & $\underset{\dot{\dot{x}}}{\mathrm{\sigma}}$ & $\underset{\infty}{\infty}$ & $\stackrel{\text { ণे }}{i}$ & $\begin{array}{l}\stackrel{\circ}{0} \\
\text { o }\end{array}$ & $\begin{array}{l}\stackrel{0}{\circ} \\
\infty \\
i\end{array}$ & $\hat{m}$ \\
\hline 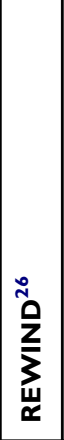 & 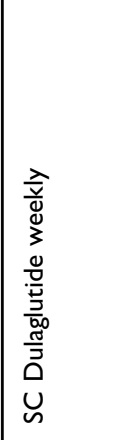 & হু & $\stackrel{\nabla}{\stackrel{H}{n}}$ & 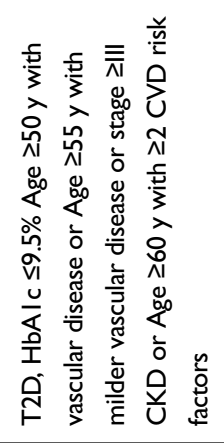 & 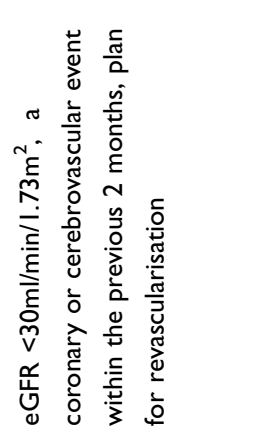 & $\frac{\text { ํํ }}{\text { i̊ }}$ & 广̊ & ః & $\stackrel{n}{\alpha}$ & ڤે & సે & $\stackrel{\stackrel{\sim}{\sim}}{ }$ & 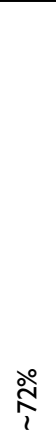 & $\hat{\mathrm{i}}$ \\
\hline 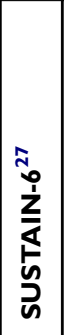 & 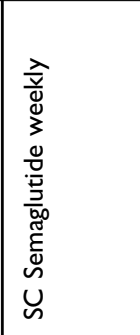 & $\underset{\text { ì }}{\stackrel{\text { }}{2}}$ & $\bar{i}$ & 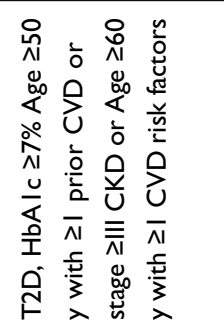 & 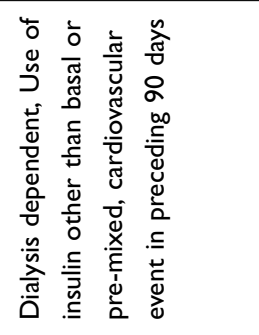 & 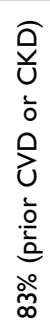 & $\stackrel{a}{i}$ & น & $\stackrel{\sigma}{\stackrel{a}{m}}$ & $\begin{array}{l}\stackrel{0}{\alpha} \\
\infty\end{array}$ & $\stackrel{\circ}{\stackrel{\circ}{ి}}$ & $\stackrel{\circ}{\circ}$ & 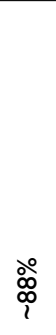 & $\stackrel{+}{\forall}$ \\
\hline 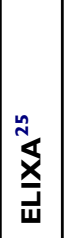 & 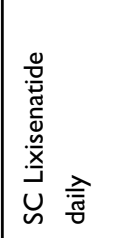 & 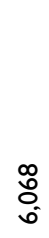 & $\bar{i}$ & 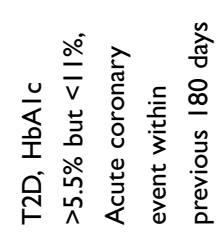 & 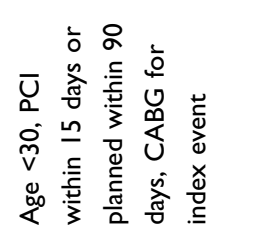 & ळे & $\bar{\imath}$ & 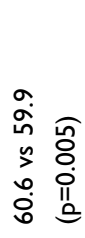 & $\underset{i}{m}$ & 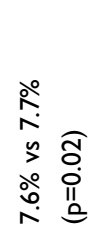 & & $\stackrel{\circ}{\stackrel{\Upsilon}{~}}$ & $\stackrel{\circ}{\circ}$ & m̧ \\
\hline 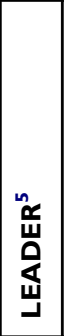 & 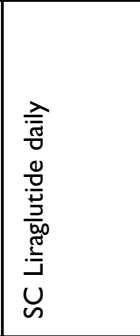 & $\begin{array}{c}\text { ơ } \\
\text { m. } \\
\text { o }\end{array}$ & $\stackrel{\infty}{m}$ & 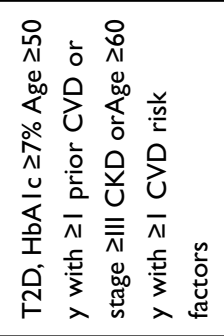 & 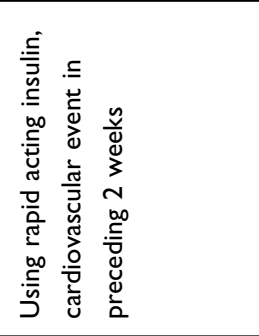 & $\frac{\stackrel{\circ}{\alpha}}{i}$ & $\stackrel{n}{\stackrel{n}{r}}$ & t & $\stackrel{\infty}{\stackrel{\infty}{\perp}}$ & $\underset{\infty}{\stackrel{\circ}{\infty}}$ & $\underset{i}{\stackrel{\circ}{\dagger}}$ & $\begin{array}{l}\stackrel{\circ}{\hat{\gamma}} \\
\stackrel{\gamma}{\gamma}\end{array}$ & 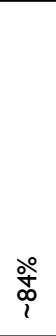 & $\stackrel{+}{m}$ \\
\hline 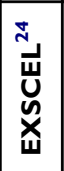 & 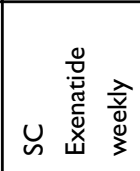 & $\begin{array}{l}\stackrel{N}{\sim} \\
\underset{ \pm}{ \pm}\end{array}$ & $\stackrel{\sim}{m}$ & 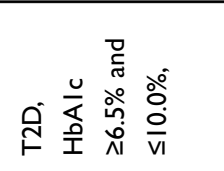 & 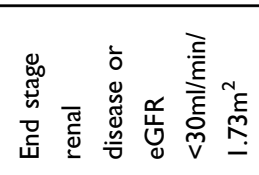 & $\frac{\partial \circ}{\dot{p}}$ & $\stackrel{\infty}{m}$ & $\widetilde{\sigma}$ & $\stackrel{\circ}{\stackrel{i}{ }}$ & ळ & $\frac{\circ}{i}$ & ஓ̊ㅇ i & $\begin{array}{l}\stackrel{\text { సे }}{\text { }} \\
\text { }\end{array}$ & $\stackrel{\leftrightarrow}{\forall}$ \\
\hline & 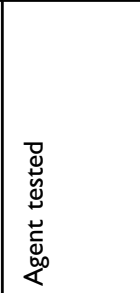 & 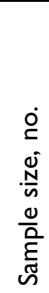 & 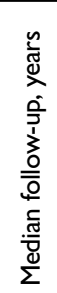 & 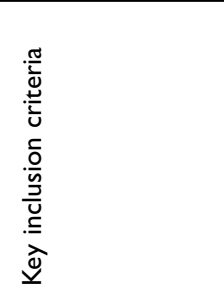 & 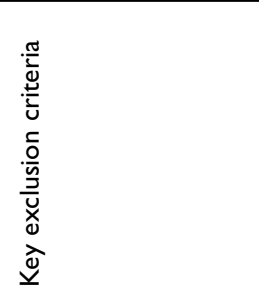 & $\begin{array}{l}0 \\
\substack{0 \\
\frac{0}{2} \\
0}\end{array}$ & 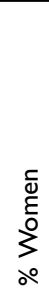 & 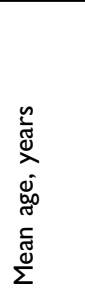 & 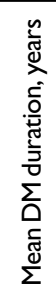 & 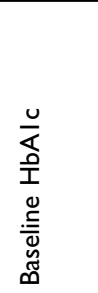 & 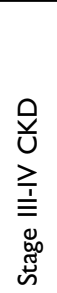 & 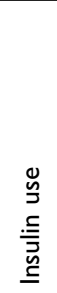 & 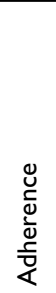 & 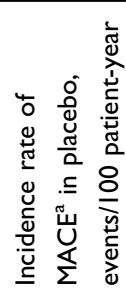 \\
\hline
\end{tabular}




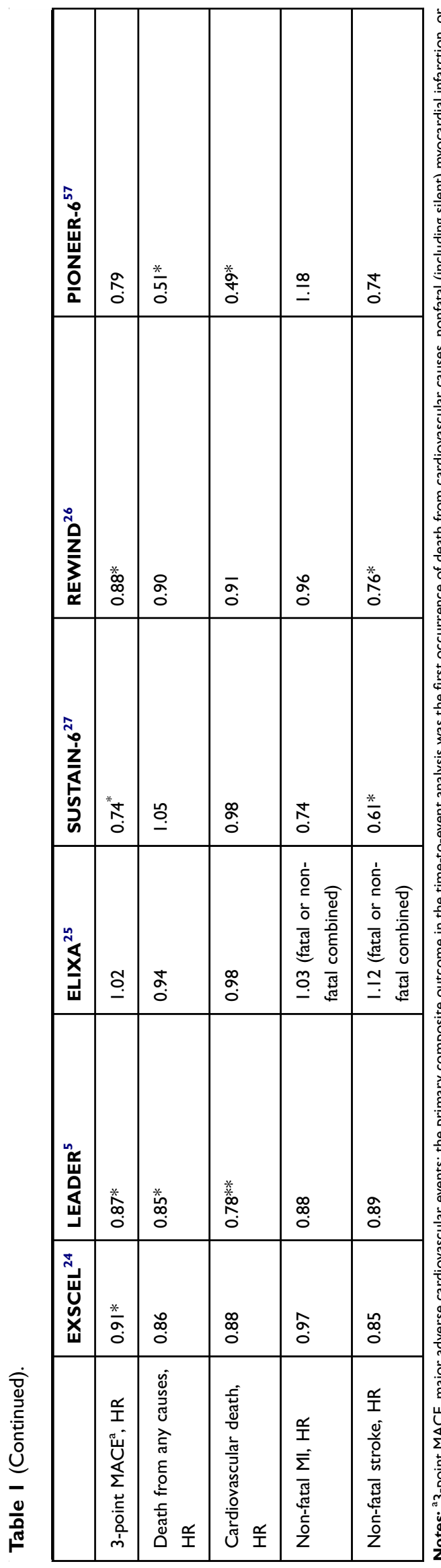

to protect GLP-1RA from early degradation in plasma, approaches used to develop liraglutide and semaglutide. Long-chain fatty acid derivatization and specific positions of amino acid substitution prevent the peptide from DPP-4 degradation and renal filtration resulting in a dramatically prolonged half-life for both liraglutide (13 hrs) and semaglutide (165 hrs) after a single injection (Figure 1). ${ }^{28}$

The challenge to develop an oral preparation for semaglutide ascribes by a hydrophilic, macromolecular peptide is naturally susceptible to low $\mathrm{pH}$ and gastric/intestinal enzymes, as well as poor gastrointestinal absorption. ${ }^{29,30}$ Salcaprozate sodium (SNAC) is an intestinal permeation

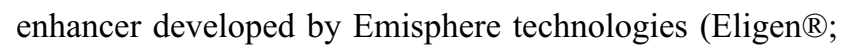
NJ, USA). Although the molecular mechanisms of SNAC enhancement of intestinal permeability are not fully understood, ${ }^{29}$ the use of SNAC to increase oral bioavailability of several peptide hormones has been proven, including salmon calcitonin, parathyroid hormone, GLP1RA, and peptide YY. ${ }^{31-34}$ Importantly, SNAC has been granted a safe status by the FDA for the use with vitamin B12. ${ }^{35}$ The pharmacokinetics study of single and multiple ascending doses of once-daily oral semaglutide in healthy and T2D subjects showed that, at steady state, the half-life of oral semaglutide co-formulated with $300 \mathrm{mg}$ SNAC was approximately $160 \mathrm{hrs} .{ }^{36}$ Recently, a mechanistic study using a pyloric-ligated dog model showed that the absorption of oral semaglutide primarily occurred via a transcellular pathway in the stomach. The authors concluded that SNAC prevented gastric degradation by neutralizing a low $\mathrm{pH}$ microenvironment surrounding the tablet, resulting in an increased concentration-dependent flux of semaglutide across the gastric mucosa ${ }^{37}$ (Figure 2).

\section{Comparisons Of Efficacy And Safety Of Oral Semaglutide And Injectable Liraglutide Or Semaglutide}

To determine efficacy and safety of oral semaglutide as monotherapy, the 26-week, phase 3, double-blinded, placebo-controlled RCT (PIONEER-1) primarily aimed to demonstrate glycemic superiority of once-daily oral semaglutide against placebo in $703 \mathrm{~T} 2 \mathrm{D}$ adults with mean age of $55 \pm 11$ years, BMI of $31.8 \pm 6.6 \mathrm{~kg} / \mathrm{m}^{2}$, baseline $\mathrm{HbA} 1 \mathrm{c}$ of $8.0 \pm 0.7 \%(63 \pm 8 \mathrm{mmol} / \mathrm{mol})$, and diabetes duration of 3.5 years. ${ }^{38}$ At week $26,3 \mathrm{mg}$, $7 \mathrm{mg}$, and $14 \mathrm{mg}$ of oral semaglutide significantly reduced $\mathrm{HbA} 1 \mathrm{c}$ from baseline by $-0.9 \%,-1.2 \%$, and $-1.4 \%$, respectively, compared to $-0.3 \%$ in the placebo 


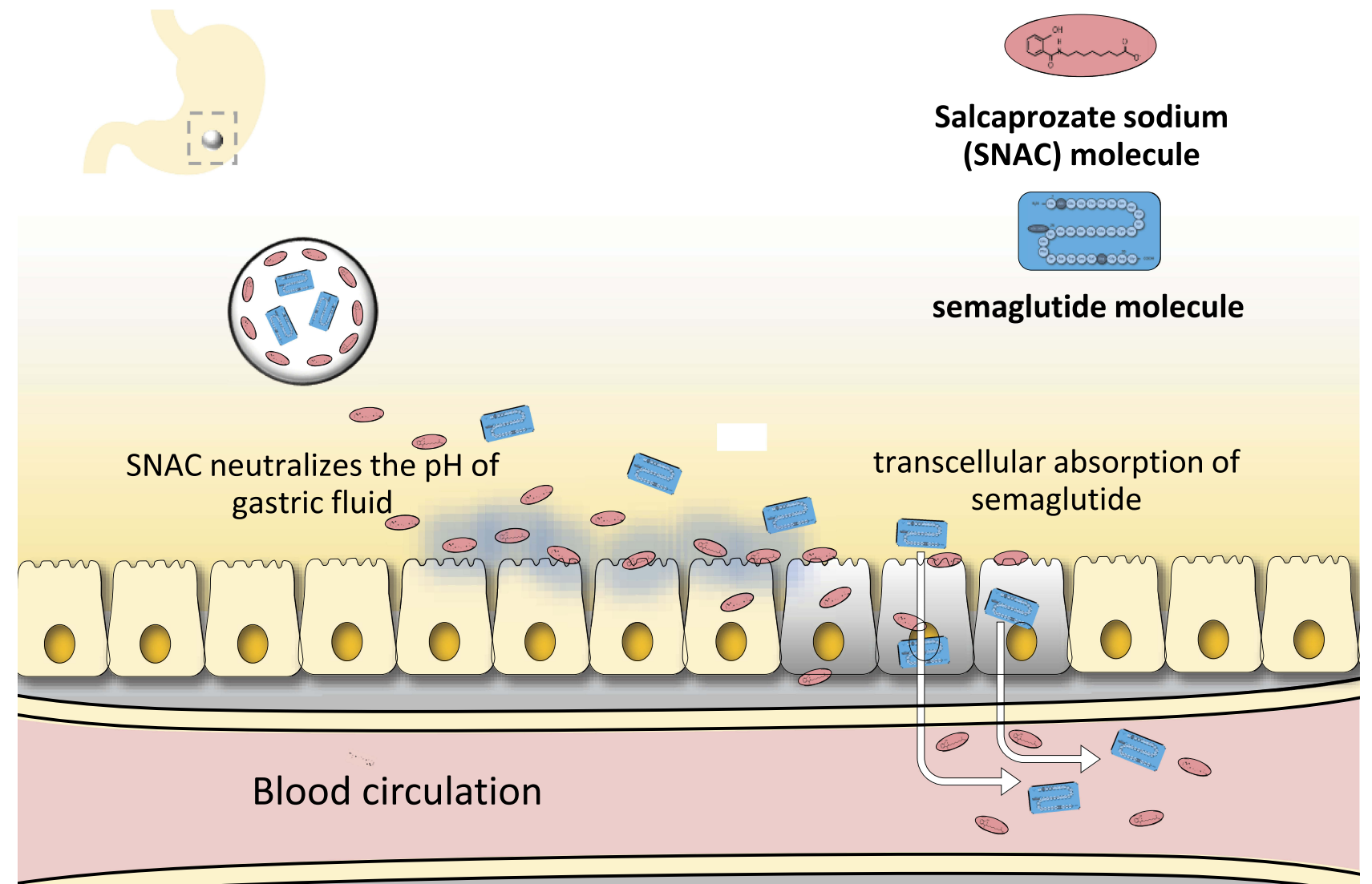

Figure 2 The mechanism of absorption of semaglutide and SNAC coformulation tablet. After digestion, the tablet is rapidly eroded and releases high concentrated amount of SNAC. SNAC neutralizes the acidic environment in the stomach by which semaglutide is protected from enzymatic degradation. In addition, SNAC also promotes monomerization of semaglutide and increases lipid membrane fluidity of gastric epithelium cells, leading to transiently enhancing semaglutide absorption via transcellular pathway without affecting tight functions. Data modified from Refs. 29 and 37.

group. Additionally, the three doses of oral semaglutide also provided superior reduction in body weight at $-1.5 \mathrm{~kg},-2.3 \mathrm{~kg}$, and $-3.7 \mathrm{~kg}$, respectively, compared to $-1.4 \mathrm{~kg}$ in the placebo group. The overall incidence of adverse events and serious adverse events including hypoglycemia was similar for both oral semaglutide and placebo; however, the $7 \mathrm{mg}$ and $14 \mathrm{mg}$ of oral semaglutide showed higher premature discontinuation rates predominantly due to gastrointestinal complaints.
A more important question is whether the oral preparation of semaglutide is as efficacious as the injectable preparations of GLP-1RA. To answer this, head-to-head studies comparing oral semaglutide and subcutaneous liraglutide or semaglutide have been conducted. The 52-week, phase 3 double-blinded RCT (PIONEER-4) directly compared the glycemic effects and body weight reduction of once-daily oral semaglutide (dose-escalated to $14 \mathrm{mg}$ ) and once-daily subcutaneous liraglutide (dose-escalated to $1.8 \mathrm{mg}$ ) among 
711 T2D participants. Mean age was $56 \pm 10$ years, BMI 33.0 $\pm 6.3 \mathrm{~kg} / \mathrm{m}^{2}, \mathrm{HbA1c} 8.0 \pm 0.7 \%$, and diabetes duration $7.6 \pm 5.5$ years, and individuals were on a stable dose of metformin $(\geq 1,500 \mathrm{mg}$ or maximum tolerated) with or without SGLT$2 \mathrm{i}^{39}$ At 26 weeks, the study showed that oral semaglutide and liraglutide decreased HBA1c by $1.2 \%$ and $1.1 \%$, respectively, indicating that oral semaglutide has similar glycemic efficacy to the well-established liraglutide injections. Moreover, oral semaglutide resulted in superior weight loss $(-4.4 \mathrm{~kg})$ compared with liraglutide $(-3.1 \mathrm{~kg} ; \mathrm{p}<0.01)$. However, adverse events leading to early discontinuation of study drug were modestly greater in oral semaglutide (11\%) than liraglutide $(9 \%)$, a difference that failed to reach statistical significance. Most discontinuations were due to gastrointestinal complaints.

Although there has been no direct head-to-head study comparing between the two preparations of semaglutide, the SUSTAIN-1 trial assessed the efficacy and safety of onceweekly subcutaneous semaglutide against placebo in 387 T2D patients using a similar study design and patient population to PIONEER-1. ${ }^{40}$ Comparing these two independent studies, oral semaglutide at $14 \mathrm{mg} /$ day was similar to $0.5 \mathrm{mg}$ of subcutaneous semaglutide in terms of glycemic and weight effect, as well as adverse events leading to premature treatment discontinuation.

\section{Comparisons Of Efficacy And Safety Between Oral Semaglutide And Other Comparators (Empagliflozin, Sitagliptin)}

The glycemic effects of oral semaglutide are at least comparable to other oral antidiabetic drugs and may even be superior. One specific class of the oral glucose-lowering drugs, SGLT-2i, is particularly interesting given their effects on glycemia, weight, and cardiovascular protection. ${ }^{4,41,42}$ The 52-week phase 3 open-labeled RCT (PIONEER-2) studied 821 T2D patients needing a second agent after metformin and demonstrated that $14 \mathrm{mg}$ of once-daily oral semaglutide was superior to $25 \mathrm{mg}$ of once-daily empagliflozin, in respect of $\mathrm{HbAlc}$ reduction. At week 52, oral semaglutide and empagliflozin decreased $\mathrm{HbA} 1 \mathrm{c}$ by $1.3 \%$ and $0.8 \%(\mathrm{p}<0.001)$, and reduced weight by $4.7 \mathrm{~kg}$ and $-3.8 \mathrm{~kg}(\mathrm{p}<0.05)$, respectively. Proportions of adverse events were similar between oral semaglutide $(70.5 \%)$ and empagliflozin $(69.2 \%)$, but premature trial product discontinuations were significantly greater with oral semaglutide (11\%) than empagliflozin $(4 \%){ }^{43}$
Generally, DPP-4 inhibitors are considered to be safe with the advantage of being well tolerated with minimal side effects. ${ }^{44}$ As an add-on therapy in 1864 T2D adults uncontrolled with metformin alone or with sulfonylurea (PIONEER-3), $7 \mathrm{mg}$ and $14 \mathrm{mg}$ of once-daily oral semaglutide were superior to $100 \mathrm{mg}$ of once-daily sitagliptin at 26 weeks, in terms of both $\mathrm{HbA1c}$ and weight reductions (HbAlc reduction of -1.0 and $-1.3 \%$ vs $-0.8 \%$, respectively; $\mathrm{p}<0.01$ for both doses), with a drop in body weight of -2.2 and $-3.1 \mathrm{~kg}$ vs $-0.6 \mathrm{~kg}$, respectively $(\mathrm{p}<0.01)$, whilst $3 \mathrm{mg}$ of oral semaglutide was noninferior to sitagliptin. ${ }^{45}$ Interestingly, overall proportion of patients experiencing at least 1 adverse event was similar across treatment groups. Only subjects taking $14 \mathrm{mg}$ of oral semaglutide had greater adverse events at $11.6 \%$, primarily gastrointestinal, leading to premature discontinuation when compared to subjects who take sitagliptin (5.2\%).

The fixed-dose approach, particularly the high dose of oral semaglutide may not sound practical especially in daily clinical practice. The flexible dose-adjustment approach allowing patients to escalate or de-escalate doses of the drug on the basis of their HbAlc and gastrointestinal tolerability (PIONEER-7) aimed to individually optimize efficacy and safety of once-daily oral semaglutide in T2D adults uncontrolled with one or two oral glucose-lowering drugs, compared to $100 \mathrm{mg} /$ day of sitagliptin. ${ }^{46}$ In this study, $9 \%, 30 \%$, and $59 \%$ of the participants had been receiving $3 \mathrm{mg}, 7 \mathrm{mg}$, and $14 \mathrm{mg}$ of once-daily oral semaglutide until week-52. HbA1c and body weight reductions were significantly greater with flexible dosing oral semaglutide group compared to sitagliptin ( $\mathrm{HbAlc}$ change from baseline was $-1.3 \%$ vs $-0.8 \%$, respectively; $\mathrm{p}<0.0001$, and weight change was $-2.6 \mathrm{~kg}$ vs $-0.7 \mathrm{~kg}$, respectively; $\mathrm{p}<0.0001$.) However, overall adverse events and premature discontinuation of trial drugs due to adverse events were still higher in oral semaglutide group despite its flexible dose adjustment.

Details of PIONEER studies relating to efficacy and safety profiles of oral semaglutide in patients with type 2 diabetes are summarized in Table 2.

\section{Comparisons Of Cardiovascular Outcomes Among Oral Semaglutide And Other Injectable GLP-IRAs}

Whilst most of injectable GLP-1RA showed superiority to placebo for primary composite vascular outcome, as 


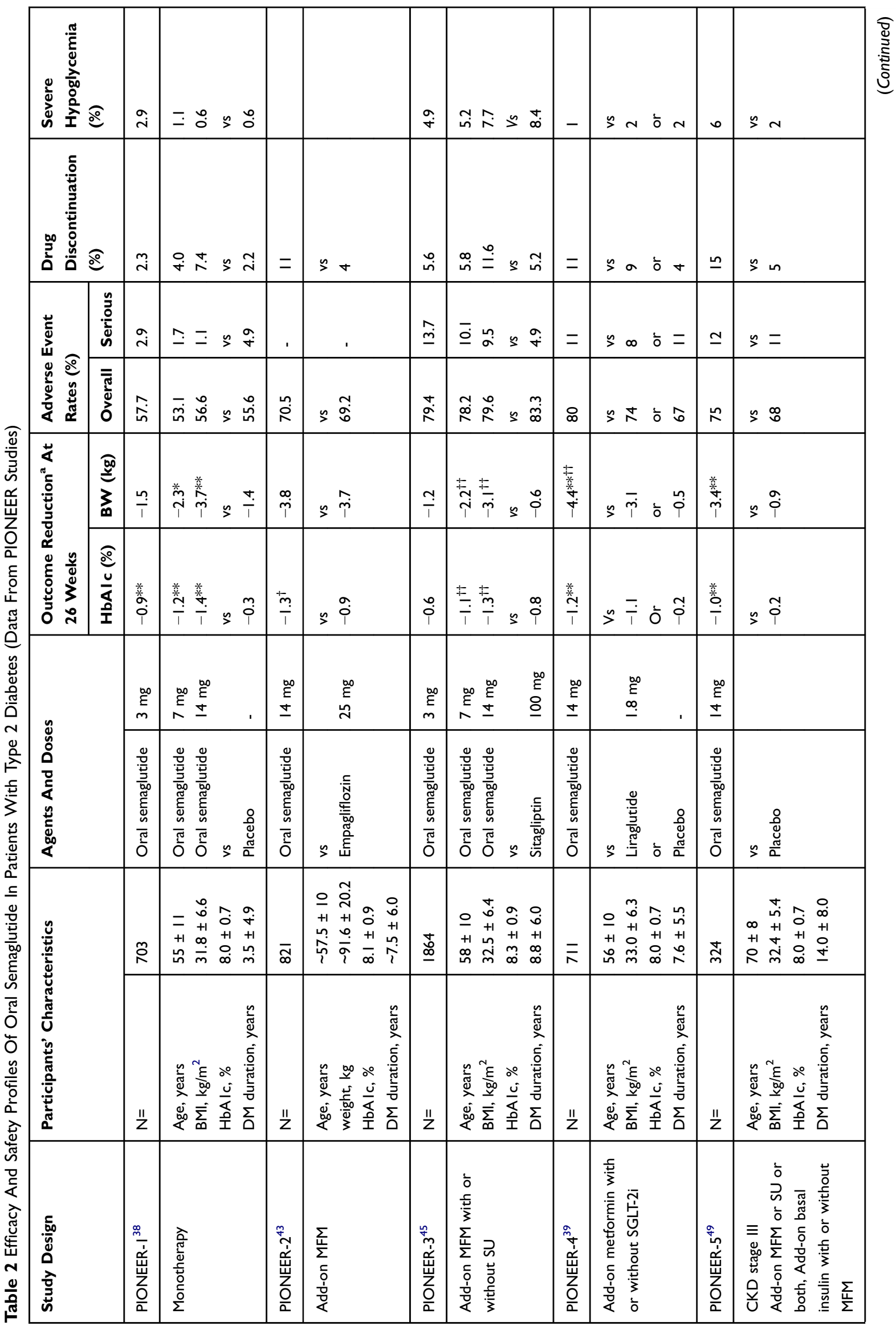




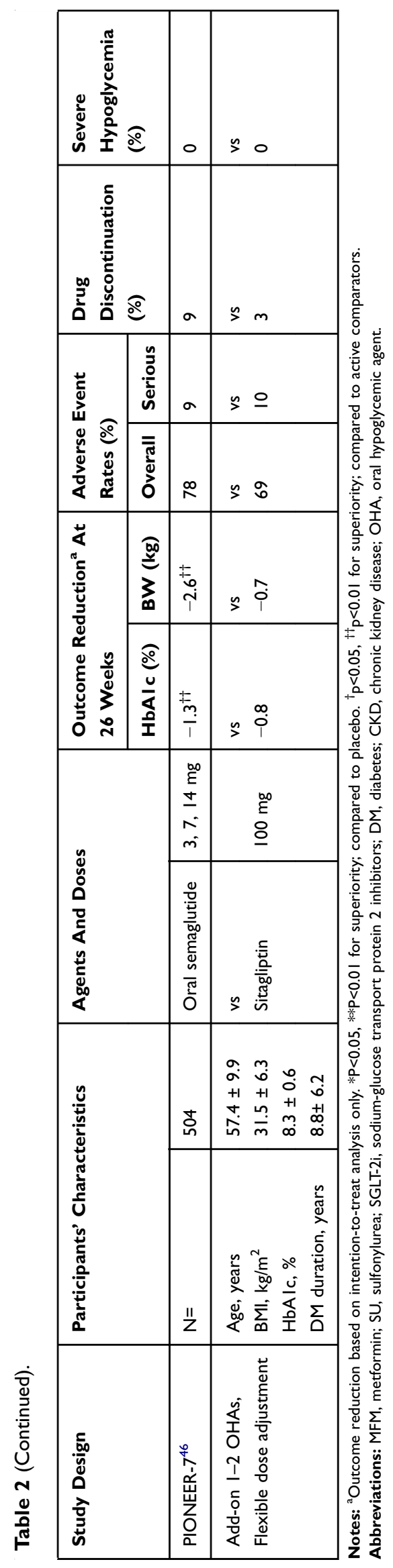

detailed earlier, oral semaglutide (PIONEER-6) confirmed only non-inferiority to placebo. ${ }^{57}$

In brief, 3183 participants who had T2D, mean age 66 \pm 7 years, mean diabetes duration $14.9 \pm 8.5$ years, and mean $\mathrm{HbAlc} 8.2 \pm 1.6 \%$ were randomly assigned to oral semaglutide or placebo. The majority were older than 50 years of age with established CVD or CKD $(85 \%)$. The median follow-up of the trial was relatively short at 15.9 months. Overall, $99.7 \%$ of the participants completed the trial where $84.7 \%$ complete the trial regimen with oral semaglutide regimen and $90.1 \%$ with placebo. Most participants $(82.1 \%)$ assigned to oral semaglutide and completed the trial were receiving the 14-mg dose by the end of the treatment period. At the end of the trial, HbAlc reduced more in oral semaglutide than placebo group $(-1.0$ vs $-0.3 \%)$ as did body weight $(-4.2 \mathrm{vs}-0.8 \mathrm{~kg})$. Major cardiovascular events occurred in $3.8 \%$ of the participants in oral semaglutide group and $4.8 \%$ in placebo group (HR: 0.79 , CI: 0.57 to $1.11 ; \mathrm{p}<0.001$ for noninferiority; $\mathrm{p}=0.17$ for superiority). Interestingly, while non-fatal events did not significantly differ, oral semaglutide clearly reduced deaths from any cause (HR: $0.51, \mathrm{CI}$ : 0.31 to 0.84 ) or cardiovascular causes (HR: 0.49 , CI: 0.27 to 0.92 ).

It should be noted that the sample size calculated for non-inferiority study design may not provide an adequate power to detect superiority. More importantly than the p-values, oral semaglutide showed a positive trend toward primary composite outcome reduction, similar to what was observed with the injectable form. Intriguingly, for secondary outcome analyses, oral semaglutide was strongly associated with all-cause and cardiovascular death reduction but not non-fatal events while dulaglutide and subcutaneous semaglutide mainly reduced non-fatal stroke but not mortality. Liraglutide was another agent in the class showing a similar mortality reduction but to a lesser degree compared to oral semaglutide.

The effects of GLP-1RA on cardiovascular outcome are not fully homogenous across studies, which may be related to the population studied and length of followup or simply due to subtle differences between the agents. Generally, however, results from cardiovascular outcome studies convey an important message that both oral and injectable formulation of human GLP-1RA appears to have beneficial effects on cardiovascular outcome in individuals with T2D. 


\section{Oral Semaglutide In Special Populations}

Semaglutide is metabolized in plasma via proteolytic cleavage of the peptide backbone and beta-oxidation of the fatty acid side chain. ${ }^{47}$ Degradation products of semaglutide, however, are excreted via urine and feces (accounted for $53.1 \%$ and $18.6 \%$ of the SC dose, respectively) implying that the kidneys and liver are involved in drug elimination. Two pharmacokinetics study of oral semaglutide in subjects with renal or hepatic impairment provided crucial information related to safety, tolerability, and doseadjustment in such populations. They drew a conclusion that oral semaglutide was well tolerated across all renal or hepatic impairment groups. ${ }^{48,58}$ No safety concerns were identified, and dose adjustment was not warranted in subjects with renal or hepatic impairment.

The phase 3 RCT of oral semaglutide add-on therapy evaluating the efficacy and safety of oral semaglutide in T2D subjects with moderate renal impairment (PIONEER-5) ${ }^{49}$ demonstrated significantly greater $\mathrm{HbAlc}$ improvement compared with placebo of $-0.8 \%$ and weight reduction of $-2.5 \mathrm{~kg}$. However, subjects on oral semaglutide had significantly higher adverse events ( $75 \%$ vs $68 \%$ ) and premature discontinuation rates $(15 \%$ vs $5 \%)$, predominantly from gastrointestinal side effects.

Oral semaglutide potentially expands the treatment options for T2D patients particularly with renal or hepatic impairment, in whom options for oral glucose-lowering agents are limited.

\section{Side Effects And Adverse Events Associated With GLP-I RA}

The most common side effect of the GLP-1RA is gastrointestinal upset. Indeed, in PIONEER 6 , a total of $6.8 \%$ of the participants discontinued oral semaglutide due to these effects. ${ }^{57}$ A similar side-effect profile is seen across the class. Rates of severe hypoglycemia have been studied in all of the major cardiovascular outcome trials barring ELIXA. ${ }^{25}$ Only the LEADER trial ${ }^{5}$ reported significantly increased rates of severe hypoglycemia, although event rate was relatively low and due to combination with insulin treatment.

There has long been a concern in the scientific community regarding the risk of pancreatitis and pancreatic cancer in those using GLP-1RA and the related DPP-4 inhibitors. This largely stems from early animal studies, ${ }^{50}$ however, data from the large cardiovascular outcome trials do not support a causal link in humans. Indeed, a meta-analysis of 4 major trials including more than 30,000 participants found no increased risk of either acute pancreatitis or pancreatic cancer in those taking GLP-1RA compared to placebo. ${ }^{59}$

Concerns were also raised about a possible link between the rare medullary thyroid carcinoma (MTC) and the use of the agents discussed in this article. A large proportion of cases of this rare disease occur as part of a genetically inherited syndrome, most commonly multiple endocrine neoplasia type 2 (MEN-2). Of note, incidence of MTC was extremely low in all of the large cardiovascular outcome trials with no significant increase seen in GLP-1RA-treated individuals, although it should be highlighted that some of the trials did have a family history of MEN-2 as an exclusion criterion. Concerns regarding a link between GLP-1 and the more common papillary thyroid carcinoma (PTC) have also been raised as cells of this lineage do express GLP-R more than normal thyroid tissue ${ }^{51}$ although evidence that the use of these drugs in humans causes increased cellular proliferation is not conclusive. Similar to MTC, there was no conclusive evidence that PTC was more common in those using GLP-1RAs in the large cardiovascular outcome trials discussed in this review.

The association between the use of GLP-1RA and the development of and/or progression of diabetic retinopathy is something which is currently under hot debate. There was an increase in cases of retinopathy in those taking oral semaglutide in PIONEER-6; however, more than $75 \%$ of these individuals required no additional treatment. ${ }^{57} \mathrm{~A}$ numerical increase in retinopathy was documented with liraglutide ${ }^{5}$ dulaglutide, ${ }^{26}$ and a significant difference in retinopathy was found with injectable semaglutide. ${ }^{27}$ In an attempt to answer the question surrounding this topic, a 2018 network meta-analysis looked at retinal complications reported in studies investigating all of the major classes of non-insulin treatments for T2D other than metformin. ${ }^{52}$ The authors concluded that the association between GLP-1RA therapies and retinopathy is uncertain and therefore this remains an area for investigation.

A summary of the side effects and adverse events reported in the major cardiovascular outcome trials in the human GLP-1RA's is shown in Table 3.

\section{Clinical Recommendations}

Oral semaglutide has already been proven to be efficacious at lowering glucose levels and it is generally well 


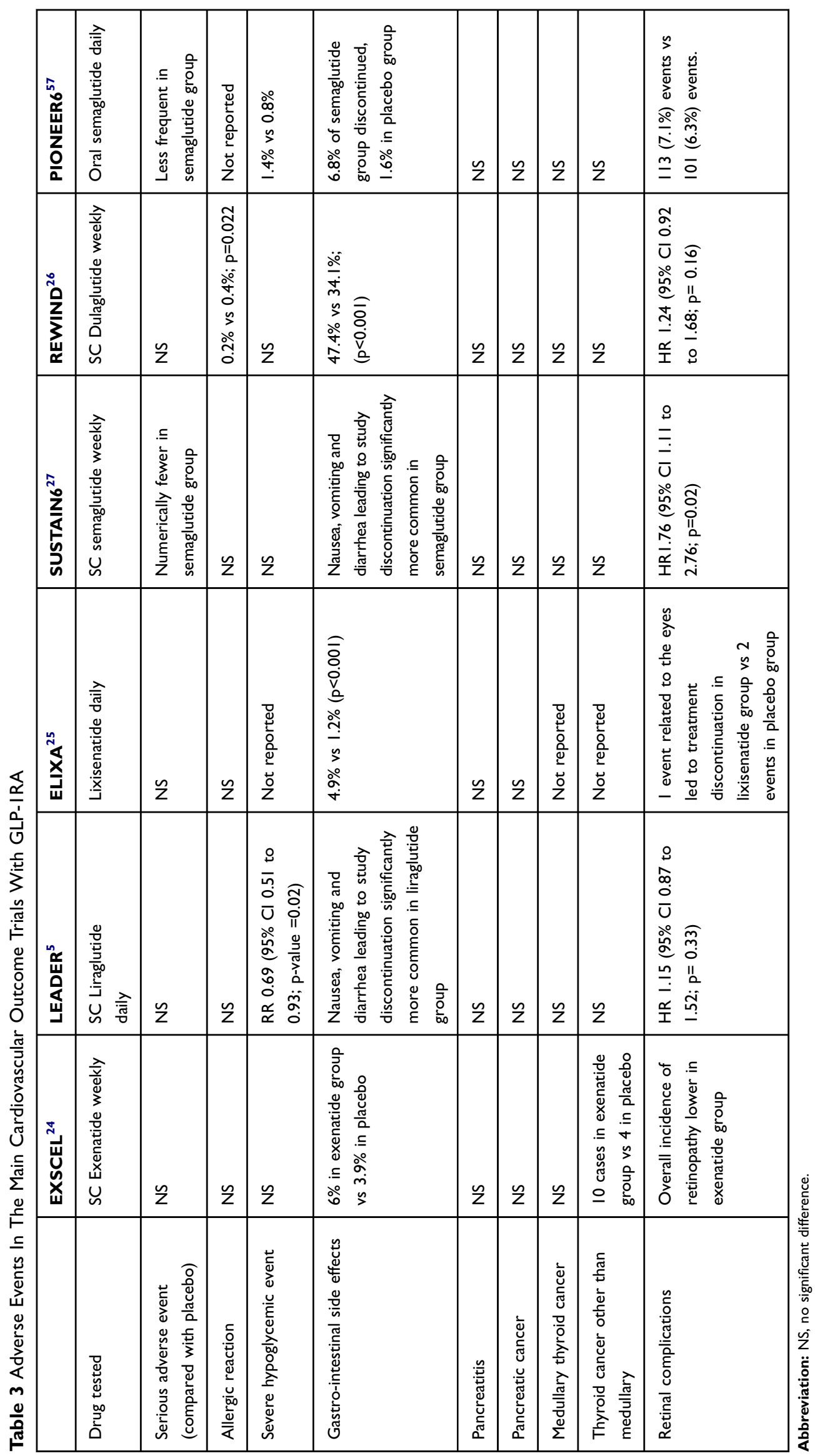


tolerated. Moreover, cardiovascular safety has been assured following the results of the PIONEER-6 study. Thus, oral semaglutide can be reasonably considered as another drug in the GLP-1RA class for treating T2D patients. Oral semaglutide should be considered as secondline therapy after metformin, particularly when weight is an issue and possibly in those at higher cardiovascular risk. $^{53}$ Oral semaglutide may also provide an additional benefit over other injectable GLP-1RA in terms of improved adherence, particularly in those with fear of injection or requiring assistance from a caregiver.

The counterargument is that SGLT- $2 \mathrm{i}$ probably has a stronger case in relation to cardiovascular protection, particularly reduction in heart failure hospitalization, but these agents can be problematic in those with urinary tract pathologies or significant renal impairment. Also, the rare, but serious, side effect of diabetic ketoacidosis can hinder their use particularly in those with longer diabetes duration and limited beta-cell reserves. The increase in hypoglycemic therapies with a favorable cardiovascular profile has revolutionized the treatment of T2D and the main drawback is the high cost associated with newer therapies. The addition of oral semaglutide is an important step forward by offering an oral hypoglycemic therapy that reduces glucose levels effectively while avoiding hypoglycemia and having positive effects on weight and cardiovascular risk.

While the treatment of diabetes is becoming more complicated, the long-term outcome of individuals with this condition has improved significantly secondary to the constant development of hypoglycemic agents and oral semagliutide represents a welcome addition to the list of glucose-lowering drugs.

\section{Abbreviations}

CKD, chronic kidney disease; CVD, cardiovascular disease; DPP-4, dipeptidyl peptidase-4; FDA, Food and Drug Administration; GLP-1, glucagon-like peptide-1; GLP-1RA, GLP-1 receptor agonists; GLP-R, GLP-receptor; MEN-2, multiple endocrine neoplasia type 2; MI, myocardial infarction; MTC, medullary Thyroid Carcinoma; PTC, papillary thyroid carcinoma; RCT, randomized controlled trial; SGLT-2i, sodium-glucose transport protein 2 inhibitors; SNAC, sodium $N$-[8-(2-hydroxybenzoyl) aminocaprylate]; T2D, type 2 diabetes; UKPDS, UK Prospective Diabetes Study.

\section{Acknowledgments}

SP is funded by the National Institute of Health Research and works within the National Health Service. NK is funded by the Faculty of Medicine, Prince of Songkla University, Thailand. Research work of RAA is currently funded by the BHF, Diabetes UK, NIHR, Abbott Diabetes Care and Avacta.

\section{Author Contributions}

SP and NK contributed equally to the work and were responsible for drafting and writing of the manuscript, searching of literature and interpreting of data. RAA was responsible for the conceptualising, drafting and writing the manuscript, interpreting the data, and critical revision of important intellectual content. All authors agreed to be accountable for all aspects of the work and approved the final version to be published.

\section{Disclosure}

RAA reports personal fees from NovoNordisk, outside the submitted work. The authors report no other conflicts of interest in this work.

\section{References}

1. Intensive blood-glucose control with sulphonylureas or insulin compared with conventional treatment and risk of complications in patients with type. 2 diabetes (UKPDS 33). UK Prospective Diabetes Study (UKPDS) Group. Lancet. 1998;352(9131):837-853.

2. Holman RR, Paul SK, Bethel MA, Matthews DR, Neil HA. 10-year follow-up of intensive glucose control in type 2 diabetes. $N$ Engl $J$ Med. 2008;359(15):1577-1589. doi:10.1056/NEJMoa0806470

3. Nissen SE, Wolski K. Effect of rosiglitazone on the risk of myocardial infarction and death from cardiovascular causes. $N$ Engl J Med. 2007;356(24):2457-2471. doi:10.1056/NEJMoa072761

4. Zinman B, Wanner C, Lachin JM, et al. Empagliflozin, Cardiovascular outcomes, and mortality in type 2 diabetes. $N$ Engl J Med. 2015;373(22):2117-2128. doi:10.1056/NEJMoa1504720

5. Marso SP, Daniels GH, Brown-Frandsen K, et al. Liraglutide and cardiovascular outcomes in type 2 diabetes. $N$ Engl J Med. 2016;375 (4):311-322. doi:10.1056/NEJMoa1603827

6. Theodorakis MJ, Carlson O, Michopoulos S, et al. Human duodenal enteroendocrine cells: source of both incretin peptides, GLP-1 and GIP. Am J Physiol Endocrinol Metab. 2006;290(3):E550-559. doi:10.1152/ajpendo.00326.2004

7. Mojsov S, Weir GC, Habener JF. Insulinotropin: glucagon-like peptide I (7-37) co-encoded in the glucagon gene is a potent stimulator of insulin release in the perfused rat pancreas. J Clin Invest. 1987;79 (2):616-619. doi:10.1172/JCI112855

8. Holst JJ. The physiology of glucagon-like peptide 1. Physiol Rev. 2007;87(4):1409-1439. doi:10.1152/physrev.00034.2006

9. Doyle ME, Egan JM. Mechanisms of action of glucagon-like peptide 1 in the pancreas. Pharmacol Ther. 2007;113(3):546-593. doi:10.1016/j. pharmthera.2006.11.007

10. Mentlein R. Dipeptidyl-peptidase IV (CD26)-role in the inactivation of regulatory peptides. Regul Pept. 1999;85(1):9-24. doi:10.1016/ S0167-0115(99)00089-0

11. Green BD, Flatt PR, Bailey CJ. Dipeptidyl peptidase IV (DPP IV) inhibitors: a newly emerging drug class for the treatment of type 2 diabetes. Diabetes Vasc Dis Res. 2006;3(3):159-165. doi:10.3132/ dvdr.2006.024 
12. Hunt JN, Smith JL, Jiang CL. Effect of meal volume and energy density on the gastric emptying of carbohydrates. Gastroenterology. 1985;89(6):1326-1330. doi:10.1016/0016-5085(85)90650-X

13. Horowitz M, Edelbroek MA, Wishart JM, Straathof JW. Relationship between oral glucose tolerance and gastric emptying in normal healthy subjects. Diabetologia. 1993;36(9):857-862. doi:10.1007/ BF00400362

14. Vrang N, Larsen PJ. Preproglucagon derived peptides GLP-1, GLP-2 and oxyntomodulin in the CNS: role of peripherally secreted and centrally produced peptides. Prog Neurobiol. 2010;92(3):442-462. doi:10.1016/j.pneurobio.2010.07.003

15. Merchenthaler I, Lane M, Shughrue P. Distribution of pre-proglucagon and glucagon-like peptide-1 receptor messenger RNAs in the rat central nervous system. J Comp Neurol. 1999;403(2):261-280. doi:10.1002/(ISSN)1096-9861

16. During MJ, Cao L, Zuzga DS, et al. Glucagon-like peptide-1 receptor is involved in learning and neuroprotection. Nat Med. 2003;9 (9):1173-1179. doi:10.1038/nm919

17. Hayes MR, Skibicka KP, Grill HJ. Caudal brainstem processing is sufficient for behavioral, sympathetic, and parasympathetic responses driven by peripheral and hindbrain glucagon-like-peptide-1 receptor stimulation. Endocrinology. 2008;149(8):4059-4068. doi:10.1210/en.2007-1743

18. Knauf C, Cani PD, Perrin C, et al. Brain glucagon-like peptide-1 increases insulin secretion and muscle insulin resistance to favor hepatic glycogen storage. J Clin Invest. 2005;115(12):3554-3563. doi:10.1172/JCI25764

19. Turton MD, O'Shea D, Gunn I, et al. A role for glucagon-like peptide-1 in the central regulation of feeding. Nature. 1996;379 (6560):69-72. doi:10.1038/379069a0

20. Tsai TH, Lee CH, Cheng CI, et al. Liraglutide inhibits endothelial-tomesenchymal transition and attenuates neointima formation after endovascular injury in streptozotocin-induced diabetic mice. Cells. 2019;8(6). doi:10.3390/cells8020137.

21. Breton-Romero R, Weisbrod RM, Feng B, et al. Liraglutide treatment reduces endothelial endoplasmic reticulum stress and insulin resistance in patients with diabetes mellitus. J Am Heart Assoc. 2018;7 (18):e009379. doi:10.1161/JAHA.118.009379

22. Egholm C, Khammy MM, Dalsgaard T, et al. GLP-1 inhibits VEGFA-mediated signaling in isolated human endothelial cells and VEGFA-induced dilation of rat mesenteric arteries. Am J Physiol Heart Circ Physiol. 2016;311(5):H1214-H1224. doi:10.1152/ ajpheart.00316.2016

23. Htike ZZ, Zaccardi F, Papamargaritis D, Webb DR, Khunti K, Davies MJ. Efficacy and safety of glucagon-like peptide-1 receptor agonists in type 2 diabetes: a systematic review and mixed-treatment comparison analysis. Diabetes Obes Metab. 2017;19(4):524-536. doi:10.1111/dom.12849

24. Holman RR, Bethel MA, Mentz RJ, et al. Effects of once-weekly exenatide on cardiovascular outcomes in type 2 diabetes. $N$ Engl J Med. 2017;377(13):1228-1239. doi:10.1056/NEJMoa1612917

25. Pfeffer MA, Claggett B, Diaz R, et al. Lixisenatide in patients with type 2 diabetes and acute coronary syndrome. $N$ Engl $J$ Med. 2015;373(23):2247-2257. doi:10.1056/NEJMoa1509225

26. Gerstein HC, Colhoun HM, Dagenais GR, et al. Dulaglutide and cardiovascular outcomes in type 2 diabetes (REWIND): a double-blind, randomised placebo-controlled trial. Lancet. 2019;394(10193):121-130.

27. Marso SP, Bain SC, Consoli A, et al. Semaglutide and cardiovascular outcomes in patients with type 2 diabetes. $N$ Engl J Med. 2016;375 (19):1834-1844. doi:10.1056/NEJMoa1607141

28. Andersen A, Lund A, Knop FK, Vilsboll T. Glucagon-like peptide 1 in health and disease. Nat Rev Endocrinol. 2018;14(7):390-403. doi:10.1038/s41574-018-0016-2

29. Twarog C, Fattah S, Heade J, Maher S, Fattal E, Brayden DJ. Intestinal permeation enhancers for oral delivery of macromolecules: a comparison between Salcaprozate Sodium (SNAC) and Sodium Caprate (C10). Pharmaceutics. 2019;11:2. doi:10.3390/pharmaceutics11020078
30. Mahato RI, Narang AS, Thoma L, Miller DD. Emerging trends in oral delivery of peptide and protein drugs. Crit Rev Ther Drug Carrier Syst. 2003;20(2-3):153-214. doi:10.1615/CritRevTher DrugCarrierSyst.v20.i23

31. Karsdal MA, Henriksen K, Bay-Jensen AC, et al. Lessons learned from the development of oral calcitonin: the first tablet formulation of a protein in phase III clinical trials. J Clin Pharmacol. 2011;51 (4):460-471. doi:10.1177/0091270010372625

32. Karsdal MA, Byrjalsen I, Henriksen K, Riis BJ, Christiansen C. Investigations of inter- and intraindividual relationships between exposure to oral salmon calcitonin and a surrogate marker of pharmacodynamic efficacy. Eur J Clin Pharmacol. 2010;66(1):29-37. doi:10.1007/s00228-009-0735-3

33. Hammerle SP, Mindeholm L, Launonen A, et al. The single dose pharmacokinetic profile of a novel oral human parathyroid hormone formulation in healthy postmenopausal women. Bone. 2012;50 (4):965-973. doi:10.1016/j.bone.2012.01.009

34. Beglinger C, Poller B, Arbit E, et al. Pharmacokinetics and pharmacodynamic effects of oral GLP-1 and PYY3-36: a proof-of-concept study in healthy subjects. Clin Pharmacol Ther. 2008;84(4):468-474. doi:10.1038/clpt.2008.35

35. Castelli MC, Wong DF, Friedman K, Riley MG. Pharmacokinetics of oral cyanocobalamin formulated with sodium N-[8-(2-hydroxybenzoyl) amino]caprylate (SNAC): an open-label, randomized, single-dose, parallel-group study in healthy male subjects. Clin Ther. 2011;33 (7):934-945. doi:10.1016/j.clinthera.2011.05.088

36. Granhall C, Donsmark M, Blicher TM, et al. Safety and pharmacokinetics of single and multiple ascending doses of the novel oral human GLP-1 analogue, oral semaglutide, in healthy subjects and subjects with type 2 diabetes. Clin Pharmacokinet. 2019;58 (6):781-791. doi:10.1007/s40262-018-0728-4

37. Buckley ST, Baekdal TA, Vegge A, et al. Transcellular stomach absorption of a derivatized glucagon-like peptide-1 receptor agonist. Sci Transl Med. 2018;10(467). doi:10.1126/scitranslmed.aar7047.

38. Aroda VR, Rosenstock J, Terauchi Y, et al. PIONEER 1: randomized clinical trial comparing the efficacy and safety of oral semaglutide monotherapy with placebo in patients with type 2 diabetes. Diabetes Care. 2019. doi: $10.2337 / \mathrm{dc} 19-0749$

39. Pratley R, Amod A, Hoff ST, et al. Oral semaglutide versus subcutaneous liraglutide and placebo in type 2 diabetes (PIONEER 4): a randomised, double-blind, phase 3a trial. Lancet. 2019;394 (10192):39-50. doi:10.1016/S0140-6736(19)31271-1

40. Sorli C, Harashima SI, Tsoukas GM, et al. Efficacy and safety of once-weekly semaglutide monotherapy versus placebo in patients with type 2 diabetes (SUSTAIN 1): a double-blind, randomised, placebo-controlled, parallel-group, multinational, multicentre phase $3 \mathrm{a}$ trial. Lancet Diabetes Endocrinol. 2017;5(4):251-260. doi:10.1016/ S2213-8587(17)30013-X

41. Wiviott SD, Raz I, Bonaca MP, et al. Dapagliflozin and cardiovascular outcomes in type 2 diabetes. N Engl J Med. 2019;380 (4):347-357. doi:10.1056/NEJMoa1812389

42. Neal B, Perkovic V, Mahaffey KW, et al. Canagliflozin and cardiovascular and renal events in type 2 diabetes. $N$ Engl J Med. 2017;377 (7):644-657. doi:10.1056/NEJMoa1611925

43. MONTANYA E, ROSENSTOCK J, LH CANANI, et al. 54-OR: oral Semaglutide vs. Empagliflozin added on to metformin monotherapy in uncontrolled type 2 diabetes: PIONEER 2. Diabetes. 2019;68 (Supplement 1):54-OR. doi:10.2337/db19-54-OR

44. Deacon CF. A review of dipeptidyl peptidase-4 inhibitors. Hot topics from randomized controlled trials. Diabetes Obes Metab. 2018;20 (Suppl 1):34-46. doi:10.1111/dom.2018.20.issue-S1

45. Rosenstock J, Allison D, Birkenfeld AL, et al. Effect of additional oral semaglutide vs sitagliptin on glycated hemoglobin in adults with type 2 diabetes uncontrolled with metformin alone or with sulfonylurea: the pioneer 3 randomized clinical trial. JAMA. 2019. doi:10.1001/ jama.2019.2942 
46. Pieber TR, Bode B, Mertens A, et al. Efficacy and safety of oral semaglutide with flexible dose adjustment versus sitagliptin in type 2 diabetes (PIONEER 7): a multicentre, open-label, randomised, phase $3 \mathrm{a}$ trial. Lancet Diabetes Endocrinol. 2019;7(7):528-539. doi:10.1016/S22138587(19)30194-9

47. Jensen L, Helleberg H, Roffel A, et al. Absorption, metabolism and excretion of the GLP-1 analogue semaglutide in humans and nonclinical species. Eur J Pharm Sci. 2017;104:31-41. doi:10.1016/j. ejps.2017.03.020

48. Granhall C, Sondergaard FL, Thomsen M, Anderson TW, Pharmacokinetics S. Tolerability of oral semaglutide in subjects with renal impairment. Clin Pharmacokinet. 2018;57(12):1571-1580. doi:10.1007/s40262-018-0649-2

49. Mosenzon O, Blicher TM, Rosenlund S, et al. Efficacy and safety of oral semaglutide in patients with type 2 diabetes and moderate renal impairment (PIONEER 5): a placebo-controlled, randomised, phase 3a trial. Lancet Diabetes Endocrinol. 2019;7(7):515-527. doi:10.1016/S22138587(19)30192-5

50. Gier B, Matveyenko AV, Kirakossian D, et al. 1 receptor activation by exendin- 4 induces expansion of pancreatic duct glands in rats and accelerates formation of dysplastic lesions and chronic pancreatitis in the $\operatorname{Kras}(\mathrm{G} 12 \mathrm{D})$ mouse model. Diabetes. 2012;61(5):1250-1262. doi: $10.2337 / \mathrm{db} 11-1109$

51. He L, Zhang S, Zhang X, Liu R, Guan H, Zhang H. Effects of insulin analogs and glucagon-like peptide-1 receptor agonists on proliferation and cellular energy metabolism in papillary thyroid cancer. Onco Targets Ther. 2017;10:5621-5631. doi:10.2147/OTT.S150701

52. Tang H, Li G, Zhao Y, et al. Comparisons of diabetic retinopathy events associated with glucose-lowering drugs in patients with type 2 diabetes mellitus: a network meta-analysis. Diabetes Obes Metab. 2018;20(5):1262-1279. doi:10.1111/dom.13232
53. Davies MJ, D'Alessio DA, Fradkin J, et al. Management of hyperglycaemia in type 2 diabetes, 2018. a consensus report by the American Diabetes Association (ADA) and the European Association for the Study of Diabetes (EASD). Diabetologia. 2018;61(12):2461-2498.

54. Lau J, Bloch P, Schaffer L, et al. Discovery of the once-weekly glucagon-like peptide-1 (GLP-1) analogue semaglutide. $J$ Med Chem. 2015;58(18):7370-7380. doi:10.1021/acs.jmedchem.5b00726

55. Knudsen LB, Lau J. The discovery and development of liraglutide and semaglutide. Front Endocrinol (Lausanne). 2019;10:155.

56. Larsen J, Hylleberg B, Ng K, Damsbo P. Glucagon-like peptide-1 infusion must be maintained for $24 \mathrm{~h}$ /day to obtain acceptable glycemia in type 2 diabetic patients who are poorly controlled on sulphonylurea treatment. Diabetes Care. 2001;24(8):1416-1421. doi: $10.2337 /$ diacare.24.8.1416

57. Husain M, Birkenfeld AL, Donsmark M, et al. Oral semaglutide and cardiovascular outcomes in patients with type 2 diabetes. $N$ Engl $J$ Med. 2019. doi:10.1056/NEJMoa1901118

58. Baekdal TA, Thomsen M, Kupcova V, Hansen CW, Anderson TW, Pharmacokinetics S. Tolerability of oral semaglutide in subjects with hepatic impairment. J Clin Pharmacol. 2018;58(10):1314-1323. doi:10.1002/jcph.1131

59. Liu Y, Tian Q, Yang J, Wang H, Hong T. No pancreatic safety concern following glucagon-like peptide-1 receptor agonist therapies: a pooled analysis of cardiovascular outcome trials. Diabetes Metab Res Rev. 2018;34(8):e3061. doi:10.1002/dmrr.v34.8

Diabetes, Metabolic Syndrome and Obesity: Targets and Therapy

Dovepress

\section{Publish your work in this journal}

Diabetes, Metabolic Syndrome and Obesity: Targets and Therapy is an international, peer-reviewed open-access journal committed to the rapid publication of the latest laboratory and clinical findings in the fields of diabetes, metabolic syndrome and obesity research. Original research, review, case reports, hypothesis formation, expert opinion and commentaries are all considered for publication. The manuscript management system is completely online and includes a very quick and fair peer-review system, which is all easy to use. Visit http://www.dovepress.com/testimonials.php to read real quotes from published authors.

Submit your manuscript here: https://www.dovepress.com/diabetes-metabolic-syndrome-and-obesity-targets-and-therapy-journal 